\title{
As excepções aos direitos de autor em benefício das bibliotecas: análise comparativa entre a União Europeia e a América Latina
}

Maria do Carmo Ferreira Dias

Mestre em Ciências Documentais. Bibliotecária da Universidade de Coimbra, Portugal

J. Carlos Fernández-Molina

Catedrático de la Facultad de Comunicación y Documentación, Universidad de Granada, España

Maria Manuel Borges

Docente do Instituto de Ciências de Informação Arquivística e Biblioteconómica, Universidade de Coimbra, Portugal

O desenvolvimento do ambiente digital tornou imprescindível uma reformulação geral da legislação sobre o direito de autor, incluindo as excepções que beneficiam as bibliotecas e instituições similares. Esta adaptação à nova realidade tecnológica, não se está a processar de uma forma satisfatória na maioria dos países, não só pelo excessivo reforço dos direitos de autor, como pela manutenção de uma certa filosofia pré-digital. Esta reforma legislativa deveria realizar-se, tendo em conta os interesses e o nível de desenvolvimento de cada país, pois os objectivos divergem entre os países da América do Norte e da Europa, em relação aos países da América Latina. $O$ objectivo deste trabalho consiste em analisar a situação em que se encontram as excepções aos direitos de autor a favor das bibliotecas, nos principais países da União Europeia e da América Latina, examinando as suas diferenças e semelhanças. Conclui-se que, apesar de as leis nacionais dos países europeus não cumprirem todos os requisitos exigidos na actualidade, contribuem para facilitar o trabalho das bibliotecas, em maior grau do que as leis dos países latino-americanos, realmente deficientes, na sua grande maioria.

Palavras-chave: Bibliotecas; Direito de autor; Legislação; América Latina; União Europeia. 


\section{Copyright exceptions for the benefit of libraries: comparative analysis between the European Union and Latin America}

The development of the digital environment it became essential a general reformation of copyright legislation, including the exceptions that benefit libraries and similar institutions. This adaptation to the new technological reality is not to process of a satisfactory form in the majority of the countries, not only for the extreme reinforcement of the copyrights, as for the maintenance of a certain pre-digital philosophy. This legislative reform would have to be become fulfilled having in account the interests and the level of development of each country, therefore the objectives diverge between the countries of the North America and the Europe, in relation to the countries of Latin America. The objective of this work consists of analyzing the situation where if they find the library exceptions in the main countries of the European Union and Latin America, examining its differences and similarities. It is concluded that, although the national laws of the European countries not to fulfill to all the requirements demanded in the actuality, contribute to facilitate the work of the libraries in bigger degree of what the laws of the Latin American countries, really deficient, in its great majority.

Keywords: Libraries; Copyright; Legislation; Latin America; European Union.

Recebido em 27.01.2010 Aceito em 10.01.2011

\section{Introdução}

O enorme desenvolvimento das tecnologias da informação e da comunicação nos últimos anos, revolucionou os modos em que as obras intelectuais podem ser criadas, difundidas e utilizadas, o que afectou directamente algumas instituições, como é o caso das bibliotecas, cuja principal missão reside em reunir e tratar estas obras para colocá-las à disposição dos utilizadores. Evidentemente, estas alterações tecnológicas tiveram, também, um impacto imediato na legislação de direitos de autor 
que, na última década, está sendo alterada e actualizada, para uma melhor adaptação ao novo ambiente digital.

Até ao momento, estas reformas legais centram-se em beneficiar os titulares dos direitos, olvidando os interesses dos utilizadores, o que pressupõe uma clara ruptura do necessário equilíbrio entre ambos os sectores. A legislação deve procurar conferir protecção aos criadores das obras para fomentar a continuação da actividade criadora, mas, também, deve facilitar o acesso às obras, para benefício da sociedade no seu conjunto.

Para conseguir o equilíbrio entre ambos os objectivos, as leis de direito de autor contam com as excepções aos direitos, isto é, nos casos em que as obras podem ser utilizadas sem autorização do titular dos direitos, quer seja de forma gratuita ou através de algum sistema de pagamento. Entre estas excepções existem umas que tiveram a sua origem, para favorecer directamente as bibliotecas e instituições similares (arquivos, museus, etc.), para que possam cumprir a sua missão de carácter social e de interesse público. Infelizmente, a sua regulação tornou-se obsoleta e resulta inapropriada para enfrentar os problemas próprios da informação digital e das redes (FERNÁNDEZ-MOLINA, 2008). De facto, esta insuficiência e inadequação ao novo ambiente têm sido estudadas, não só pelos comités de peritos (LIBRARY OF CONGRESS, 2008), mas, também, pelas organizações bibliotecárias internacionais (LIBRARY COPYRIGHT ALLIANCE, 2004; EIFL, 2009; IFLA, 2009). Mas, o mais importante deste movimento reside no facto de a Organização Mundial da Propriedade Intelectual (OMPI) ter posto em marcha um processo de estudo e avaliação da situação, cujo fruto mais significativo, até à presente data, consiste no estudo elaborado pelo professor Kenneth Crews (2008), no qual se realiza uma revisão geral das excepções em favor das bibliotecas, em quase 150 países do mundo.

A análise do facto de as excepções em favor das bibliotecas serem ou não adequadas no momento actual, não é apenas uma questão de obsolescência e falta de adaptação ao novo ambiente digital. Deve, também, enquadrar-se no seu contexto socioeconómico, em especial, porque se trata de países desenvolvidos ou em vias de desenvolvimento. Neste aspecto, os países em vias de desenvolvimento, como os que fazem parte da América Latina (ainda que tenham diferenças importantes entre eles) não apresentam as mesmas necessidades e os mesmos interesses, dos países ricos da Europa e da América do Norte.

O objectivo deste trabalho consiste em analisar a situação em que se encontram as excepções aos direitos de autor que beneficiam as bibliotecas, nos principais países da União Europeia e da América Latina, examinando as suas diferenças e semelhanças. Para isso, incidimos, primeiramente, sobre as excepções aos direitos de autor, a sua tipologia e os seus objectivos. Posteriormente, centramos a nossa atenção, nas que mais nos interessam: os privilégios das bibliotecas. Em seguida, analisamos o modo como regulam estas excepções, as leis nacionais de direitos de autor dos 15 principais países da União Europeia e dos 11 mais 
importantes países da América Latina. Para a pesquisa das várias leis dos países, a fonte de informação consultada foi a base de dados CLEA (Colección de Leyes Electrónicamente Accesible), mantida e actualizada pela OMPI ${ }^{1}$.

\section{As excepções do direito de autor}

O Direito de Autor tem evoluído ao longo dos tempos. A sua origem remonta até à Antiguidade Clássica e o seu desenvolvimento foi marcado pela invenção da imprensa e pela revolução industrial. Com a expansão deste direito, surgiu a necessidade de começar a legislar sobre este domínio. Garrett (1849), citado por Pereira (2001, p.113) afirmava: "a mais indefesa, porém, a mais nobre e a mais inquestionável de todas as propriedades, a que se cria pela inteligência e pelo espírito do Homem". Stewart (1989, p. 185) insistia que a evolução do direito de autor "reflecte o desenvolvimento da tecnologia".

A nível internacional, procurou-se legislar sobre este domínio, tendo sido publicadas as primeiras leis no século XVIII, na Inglaterra e França. Com o desenrolar do tempo, novas legislações foram surgindo e verificouse a necessidade de harmonizar as várias disposições existentes. Nesta linha, aprovou-se a Convenção de Berna, que incide sobre a protecção das obras literárias e artísticas e que é considerada como um dos actos internacionais com maior relevo no séc. XIX. Stewart (1989) afirma que a Convenção de Berna constitui «a magna carta do direito de autor». Esta Convenção foi um marco muito importante, não só porque institui as traves mestras do direito de autor, mas outrossim, porque serviu de base para futuras legislações neste domínio. O texto desta Convenção alude a certas referências sobre as excepções ou limitações, ressalvando a possibilidade de regulação por parte dos países. No artigo $10^{\circ} ., \mathrm{n}^{0} .1 \mathrm{da}$ Convenção de Berna, constata-se: "são lícitas as citações tiradas de uma obra já licitamente tornada acessível ao público, na condição de serem conformes aos bons costumes e na medida justificada para o fim a atingir..." (OMPI, 1971).

Mais recente é o Tratado de Direito de Autor da OMPI (1996), que complementa a Convenção de Berna com o objectivo de adaptá-la ao universo do digital (RICKETSON, 2003). Incide, também, a sua aplicação sobre as limitações ao direito de autor. No artigo $10^{\circ}$. do Tratado concede-se a possibilidade de os países intervenientes poderem "prever, nas suas legislações nacionais, limitações ou excepções aos direitos concedidos aos autores de obras literárias e artísticas", salvaguardando a "exploração normal da obra" e algum «prejuízo injustificado aos interesses legítimos do autor" (OMPI, 1996). Entre estas excepções encontram-se as que beneficiam as bibliotecas que, portanto, podem ser aplicadas e adaptadas à nova realidade tecnológica (FERNÁNDEZ-MOLINA; DIAS; BORGES, 2008).

\footnotetext{
${ }^{1}$ Disponível em: <http://www.wipo.int/clea/es>. Acesso em: 18 jan. 2010.
} 
Na União Europeia, várias Directivas foram aprovadas sobre o direito de autor. Convém realçar a importância da directiva sobre a harmonização de certos aspectos do direito de autor e dos direitos conexos da sociedade de informação (UNIÃO EUROPEIA, 2001). Esta directiva comunitária é considerada como uma das mais importantes medidas legislativas, no território do direito de autor, contribuindo para a prossecução dos objectivos da União Europeia, nomeadamente, para o bom funcionamento do mercado interno, para a livre concorrência e para a confirmação das liberdades fundamentais do mercado interno. A Directiva 2001/29/CE tem por base os princípios patentes no Tratado da OMPI de 1996, alargando o seu universo às novas realidades da digitalização e do multimédia e às novas tecnologias, tendo sempre presentes os objectivos da União Europeia. Apresenta algumas disposições de carácter obrigatório para os Estados membros e outras de carácter facultativo, nas quais se incluem as excepções em prol das bibliotecas. Prevê a possibilidade de os Estados membros ampliarem essas excepções ou limitações.

As excepções ou limitações caracterizam-se por serem várias e por serem dependentes de outros factores como a defesa dos direitos fundamentais, as competências, o interesse público e as imperfeições do mercado (GUIBAULT, 2002). O interesse público constitui a base dos privilégios atribuídos às bibliotecas e instituições similares, como os museus, os arquivos, as hemerotecas, etc., realçando as funções que desenvolvem estas instituições, tais como: a colecção, a preservação e a difusão da informação. Estas limitações ou excepções detêm uma importância muito relevante e estão presentes no texto das várias legislações dos países, mau grado algumas diferenças patentes, como os actos que são ou não autorizados, as renumerações exigidas e o tipo de instituições que auferem destes privilégios. As instituições sobre as quais recaem estas limitações ou excepções são instituições direccionadas para a preservação e difusão da informação e que comportam vantagens para a sociedade e para a promoção do bem comum.

\section{Os privilégios das bibliotecas}

As bibliotecas desenvolvem um importante papel na sociedade, conservando o património documental. Preservam a memória cultural e científica da Humanidade e constituem a chave para o acesso ao conhecimento e à informação. Guibault (2003, p.12) refere: "typical functions of any library are the collection, preservation, archiving and dissemination of information". As bibliotecas são consideradas forças vivas "para a educação, cultura e informação" (UNESCO, 1994).

Devido à acção preponderante que as bibliotecas desempenham, as legislações dos vários países concedem-lhes determinadas excepções ou limitações, que constituem autênticos privilégios. Estes privilégios são atribuídos às bibliotecas, que efectuam um serviço público e a determinadas instituições com carácter cultural ou científico, sem fins comerciais. 
Os privilégios são excepções ou limitações ao direito de autor, que se caracteriza por não ser um direito absoluto. Representam aspectos legislativos considerados muito relevantes para a acção que as bibliotecas desenvolvem na sociedade, nomeadamente para o acesso fácil e rápido à informação. Os privilégios constituem, pois, determinadas prerrogativas que as bibliotecas podem colocar em prática, de acordo com os fins de conservação, de preservação e de divulgação da informação (CREWS, 2008).

Os privilégios, que se definem como excepções ou limitações ao direito de autor, são constituídos por certas disposições que restringem os direitos concedidos aos titulares dos direitos de autor, com certos objectivos estabelecidos, sendo os mais comuns a investigação e a preservação. São atribuídos às bibliotecas, que são instituições públicas, que prestam um serviço à sociedade e que não possuem quaisquer fins lucrativos. Conservam, tornam acessível e preservam o património documental (DREIER, 2001).

Podemos, assim, destacar a reprodução de obras, que se encontram protegidas pelo direito de autor; a comunicação pública, a distribuição e a colocação à disposição dos utilizadores, por parte de bibliotecas ou outras instituições similares. Os privilégios englobam, também, o mundo do digital e devem procurar não prejudicar a normal exploração da obra e não colidir com os interesses dos direitos de autor.

Estas disposições jurídicas relativas aos privilégios concedidos às bibliotecas constam das legislações da quase totalidade dos países. Embora, certas legislações de alguns países sejam omissas quanto a esta matéria. Este facto não implica que as bibliotecas desses países não possam proceder legitimamente a cópias de obras protegidas pelo direito de autor.

As limitações ou excepções ao direito de autor atribuídas às bibliotecas representam autênticos privilégios, que são concedidos a instituições que detêm um papel importantíssimo na sociedade e que prestam um serviço público, sem qualquer finalidade económica. A atribuição destes privilégios manifesta o reconhecimento do papel que as bibliotecas desenvolvem na sociedade actual, preservando e conservando o património cultural e patrimonial da Humanidade. Como escreve Crews (2008, p. 36): "las bibliotecas tienen evidentemente un papel principal en el contexto de la legislación sobre derecho de autor".

As legislações dos vários países são diferentes e podemos constatar que varia muito o que é lícito copiar. Alguns países, com as suas legislações mais permissivas, permitem a cópia de todo o tipo de obras, enquanto outros países impõem algumas restrições quanto ao tipo de obras. Convém referir, que os fundos documentais das bibliotecas, hoje em dia, são, também, constituídos por documentos em suporte digital, o que levanta outros problemas de preservação e de conservação.

Das excepções ou limitações mais relevantes, podemos referenciar as excepções gerais que permitem às bibliotecas realizar a reprodução de obras protegidas pelos direitos de autor, sem nenhum objectivo específico 
e com uma certa flexibilidade. Mas, ao mesmo tempo, podemos considerar outros tipos de excepções, como:

\subsection{As excepções para fins de investigação e estudo}

As disposições legais com a finalidade de investigação e estudo encontram-se presentes na quase totalidade das legislações dos vários países. Incidem sobre a possibilidade de se realizarem cópias e sobre a colocação à disposição dos utilizadores. Estas excepções podem ser mais gerais ou mais específicas. As bibliotecas podem ser autorizadas a efectuar cópias de todo o tipo de obras ou apenas cópias de algumas obras específicas, por exemplo as pertencentes às colecções das bibliotecas ou de obras publicadas. As obras não publicadas são objecto de uma atenção especial, devido à importância que detêm para a investigação e para o estudo. Pode ser necessário, ainda, a realização de cópias para sua preservação. Nalguns casos, é exigida a prova da finalidade da cópia.

\subsection{As excepções para fins de preservação e substituição}

As bibliotecas têm como missão a preservação e a conservação dos seus fundos documentais. Para cumprir estes objectivos, por vezes, é necessário proceder, por meios lícitos, a cópias das obras, que se encontram protegidas pelos direitos de autor. As obras antigas, algumas em mau estado, podem correr riscos de deterioração; as obras modernas, por vezes impressas em papéis ácidos podem decompor-se e as publicações periódicas muito consultadas podem correr o risco de se perderem. Estes factos demonstram bem a importância das reproduções para a preservação e para a conservação do património documental.

A reprodução para preservar permite a cópia de uma obra, de forma a evitar a sua perda. A reprodução para substituir implica a cópia para substituição na colecção da biblioteca. A substituição encontra-se associada à preservação.

Estas excepções caracterizam-se por uma certa dualidade. Por um lado, as cópias para preservar e conservar são possíveis devido ao facto de existirem riscos de perdas das obras, o que implicaria consequências profundas para o legado cultural da sociedade. Por outra banda, as cópias originam perdas comerciais e perdas de receitas para os titulares dos direitos.

Também não podemos esquecer os problemas que surgem com a conservação e preservação dos novos tipos de suportes dos documentos e da informação digital que circula nas redes e que fazem parte do património cultural. 


\subsection{As excepções para fornecimento de documentos ou para empréstimos interbibliotecas}

Esta excepção é de grande relevância, em virtude de, permitir o acesso aos fundos documentais de outras bibliotecas, facilitando o acesso à informação e ao conhecimento. Trata-se de uma excepção muito importante para as bibliotecas, mas, ao mesmo tempo, pode ser um obstáculo à venda comercial das obras.

Importa aludir, ainda, a existência de outras excepções como a possibilidade de se efectuarem cópias mediante a existência de máquinas fotocopiadoras nas bibliotecas; os limites das disposições jurídicas que se encontram em vigor $e$, por fim, o contornamento das medidas tecnológicas (CREWS, 2008).

\section{Análise comparativa dos países da União Europeia}

No caso dos países da União Europeia, a reforma das suas legislações nacionais teria que utilizar como ponto de partida a Directiva de 2001. Dado que as excepções aos direitos, incluídas no seu artigo 50, são de carácter facultativo, cada país decidiu quais devia incluir e quais não. Na realidade, as excepções em favor das bibliotecas já estavam presentes nas leis de todos estes países, no entanto, na transposição da directiva, realizaram-se diversas modificações e adições (FERNÁNDEZMOLINA, 2009).

Dois artigos da directiva aplicam-se às bibliotecas. O primeiro a referenciar é o artigo $5^{\circ} ., \mathrm{n}^{\circ} .2$, alínea c), que confere a possibilidade de se preverem excepções ou limitações ao direito de reprodução, mais concretamente, para "actos específicos de reprodução praticados por bibliotecas [...], que não tenham por objectivo a obtenção de uma vantagem económica ou comercial, directa ou indirecta" (UNIÃO EUROPEIA, 2001). Convém assinalar que não faz referência a que a cópia seja reprográfica ou digital, pelo qual podia reportar-se a ambas e, do mesmo modo, não alude ao facto de ser necessário renumerar os titulares dos direitos, por estas reproduções.

Mas, além disto, existe um segundo artigo, que pela primeira vez, introduz a possibilidade de o direito de comunicação pública esteja limitado. Em concreto, o artigo 50, n. 3, alínea n) alarga o âmbito das limitações ou excepções, incidindo, também, sobre a «utilização por comunicação ou colocação à disposição, para efeitos de investigação ou estudos privados, a membros individuais do público por terminais destinados para o efeito nas instalações referidos na alínea c) do no 2, de obras e outros materiais e outros materiais não sujeitos a condições de compra ou licenciamento que fazem parte das suas colecções» (UNIÃO EUROPEIA, 2001). Quer dizer, sem autorização dos titulares dos direitos, pode-se levar a cabo a comunicação pública de obras das suas colecções, sempre que se realize nas instalações da biblioteca (sem acesso externo), com a finalidade de investigação e estudo privado e, desde que sejam 
obras que não se encontrem sujeitas a contrato de licença, o que limita muito a sua aplicação, como acertadamente defende Garrote (2001).

Dado que a directiva constitui, apenas, um ponto de partida, cada país tem uma margem de liberdade para a adaptar às suas necessidades e circunstâncias concretas. Portanto, o resultado demonstra que a legislação dos países membros é semelhante, mas não é idêntica. Na TAB. 1 resumem-se as características essenciais da lei dos 15 países mais antigos da União Europeia. Para o seu desenho, utilizaram-se várias variáveis. Em primeiro lugar, a finalidade que permite que a biblioteca ou arquivo beneficie da excepção ao direito de autor. Em segundo, a instituição que pode ser beneficiada, sendo o habitual que sejam as bibliotecas, arquivos e museus, ainda que, em determinados casos, não estejam incluídos estes últimos. Dado que os direitos afectados e incluídos nesta directiva, são a reprodução e a comunicação pública, as variáveis seguintes analisam o que se pode copiar ou comunicar e quais as condições possíveis. Por último, analisa-se se existe uma excepção que permita que o empréstimo público nas bibliotecas não se encontre ligado ao direito de distribuição.

TABELA 1 - As excepções para as Bibliotecas na legislação da União Europeia

\begin{tabular}{|c|c|c|c|c|c|}
\hline Países & Finalidade & Instituições & Reprodução & $\begin{array}{l}\text { Comunicação } \\
\text { Pública }\end{array}$ & $\begin{array}{l}\text { Emprés- } \\
\text { timo }\end{array}$ \\
\hline Alemanha & $\begin{array}{l}\text { Investigação } \\
\text { Estudo privado }\end{array}$ & $\begin{array}{l}\text { Bibliotecas, } \\
\text { Museus e } \\
\text { Arquivos }\end{array}$ & $\begin{array}{l}\text { Fragmentos das } \\
\text { obras da colecção e } \\
\text { artigos de revista }\end{array}$ & $\begin{array}{l}\text { Obras da sua } \\
\text { colecção } \\
\text { Permitido pela licença }\end{array}$ & Não \\
\hline Áustria & $\begin{array}{l}\text { Sem finalidade } \\
\text { concreta }\end{array}$ & $\begin{array}{l}\text { Estabel. } \\
\text { acessíveis ao } \\
\text { público }\end{array}$ & Obras publicadas & Não & Não \\
\hline Bélgica & Preservação & $\begin{array}{l}\text { Bibliotecas, } \\
\text { Museus e } \\
\text { Arquivos }\end{array}$ & Obras publicadas & $\begin{array}{l}\text { Obras da sua } \\
\text { colecção } \\
\text { Permitido pela licença }\end{array}$ & Não \\
\hline Dinamarca & $\begin{array}{l}\text { Preservação } \\
\text { Substituição }\end{array}$ & $\begin{array}{l}\text { Bibliotecas, } \\
\text { Arquivos Públicos }\end{array}$ & $\begin{array}{l}\text { Obras publicadas } \\
\text { Faltas na colecção, } \\
\text { obras não } \\
\text { disponíveis }\end{array}$ & $\begin{array}{l}\text { Obras da sua } \\
\text { colecção } \\
\text { Permitido pela licença }\end{array}$ & Não \\
\hline Espanha & $\begin{array}{l}\text { Investigação } \\
\text { Preservação }\end{array}$ & $\begin{array}{l}\text { Bibliotecas, } \\
\text { Museus e } \\
\text { Arquivos }\end{array}$ & $\begin{array}{l}\text { Obras da sua } \\
\text { colecção }\end{array}$ & $\begin{array}{l}\text { Obras da sua } \\
\text { colecção } \\
\text { Permitido pela licença }\end{array}$ & Sim \\
\hline Finlândia & $\begin{array}{l}\text { Preservação } \\
\text { Administração da } \\
\text { colecção } \\
\text { Restauração } \\
\text { Completar uma } \\
\text { obra }\end{array}$ & $\begin{array}{l}\text { Bibliotecas, } \\
\text { Museus e } \\
\text { Arquivos }\end{array}$ & $\begin{array}{l}\text { Obras da sua } \\
\text { colecção } \\
\text { Obras publicadas } \\
\text { vulneráveis }\end{array}$ & $\begin{array}{l}\text { Obras da sua } \\
\text { colecção } \\
\text { Permitido pela licença }\end{array}$ & Não \\
\hline França & $\begin{array}{l}\text { Preservação } \\
\text { Consulta dos } \\
\text { utilizadores }\end{array}$ & $\begin{array}{l}\text { Bibliotecas, } \\
\text { Museus e } \\
\text { Arquivos }\end{array}$ & Obras & Não & Não \\
\hline Grécia & $\begin{array}{l}\text { Conservação } \\
\text { Cópias para outras } \\
\text { bibliotecas }\end{array}$ & $\begin{array}{l}\text { Bibliotecas e } \\
\text { Arquivos }\end{array}$ & Obras da colecção & Não & Sim \\
\hline Holanda & $\begin{array}{l}\text { Preservação } \\
\text { Substituição }\end{array}$ & $\begin{array}{l}\text { Bibliotecas, } \\
\text { Museus e } \\
\text { Arquivos }\end{array}$ & Obras da colecção & $\begin{array}{l}\text { Obras da sua } \\
\text { colecção } \\
\text { Permitido pela licença }\end{array}$ & Sim \\
\hline Irlanda & $\begin{array}{l}\text { Investigação e } \\
\text { estudo } \\
\text { Preservação } \\
\text { Substituição } \\
\text { Administração das } \\
\text { bibliotecas }\end{array}$ & $\begin{array}{l}\text { Bibliotecas e } \\
\text { Arquivos }\end{array}$ & $\begin{array}{l}\text { Obras da colecção } \\
\text { Artigos e } \\
\text { fragmentos de } \\
\text { obras }\end{array}$ & Não & Sim \\
\hline
\end{tabular}




\begin{tabular}{|c|c|c|c|c|c|}
\hline Itália & $\begin{array}{l}\text { Uso bibliotecário } \\
\text { Uso pessoal }\end{array}$ & $\begin{array}{l}\text { Bibliotecas, } \\
\text { Museus e } \\
\text { Arquivos }\end{array}$ & $\begin{array}{l}\text { Obras da colecção } \\
\text { Não são permitidas } \\
\text { cópias digitais }\end{array}$ & $\begin{array}{l}\text { Obras da sua } \\
\text { colecção } \\
\text { Permitido pela licença }\end{array}$ & Sim \\
\hline Luxemburgo & Preservação & $\begin{array}{l}\text { Bibliotecas, } \\
\text { Museus e } \\
\text { Arquivos }\end{array}$ & Obras publicadas & $\begin{array}{l}\text { Obras da sua } \\
\text { colecção } \\
\text { Permitido pela licença }\end{array}$ & Não \\
\hline Portugal & $\begin{array}{l}\text { Preservação } \\
\text { Arquivo }\end{array}$ & $\begin{array}{l}\text { Bibliotecas, } \\
\text { Museus e } \\
\text { Arquivos }\end{array}$ & Obras publicadas & $\begin{array}{l}\text { Obras da sua } \\
\text { colecção } \\
\text { Permitido pela licença }\end{array}$ & Não \\
\hline Reino Unido & $\begin{array}{l}\text { Preservação } \\
\text { Substituição } \\
\text { Investigação e } \\
\text { estudo }\end{array}$ & $\begin{array}{l}\text { Bibliotecas e } \\
\text { Arquivos }\end{array}$ & $\begin{array}{l}\text { Obras da colecção } \\
\text { Artigos e } \\
\text { fragmentos de } \\
\text { obras } \\
\text { Obras não } \\
\text { publicadas }\end{array}$ & Não & Sim \\
\hline Suécia & $\begin{array}{l}\text { Preservação } \\
\text { Completar obras } \\
\text { incompletas } \\
\text { Investigação }\end{array}$ & $\begin{array}{l}\text { Bibliotecas e } \\
\text { Arquivos }\end{array}$ & $\begin{array}{l}\text { Obras } \\
\text { Artigos e } \\
\text { fragmentos de } \\
\text { obras }\end{array}$ & Não & io \\
\hline
\end{tabular}

Fonte: Dados da pesquisa.

No que concerne, aos propósitos, importa referir que a Áustria é o único país que não expõe uma finalidade expressa. Na Bélgica, na Dinamarca, na Espanha, na Finlândia, na França, na Holanda, na Irlanda, em Luxemburgo, no Reino Unido e na Suécia, a primazia das finalidades destas medidas recai sobre a preservação e sobre a substituição. Em Portugal, apenas incide sobre a substituição e o arquivo. Na Grécia, o destaque reside na conservação e nas cópias para outras bibliotecas e no Luxemburgo na salvaguarda do património. Na Alemanha, na Espanha, na Irlanda, na Itália, no Reino Unido e, por fim, na Suécia, podemos referir os fins de acordo com a investigação e com o estudo. Na Finlândia, na Grécia, na Irlanda e na Itália, as finalidades visam a própria administração das bibliotecas. A Dinamarca e a Suécia têm, a particularidade, da exigência de uma licença colectiva.

Quanto às instituições consideradas, a legislação da Áustria alude aos estabelecimentos acessíveis ao público. Noutros Estados membros, como a Grécia, a Irlanda, o Reino Unido e a Suécia, as disposições legislativas recaem apenas sobre as bibliotecas e arquivos públicos. Contudo, na Alemanha, na Bélgica, na Dinamarca, na Finlândia, na França e na Holanda, incidem a sua acção sobre as bibliotecas, museus e arquivos. Em certos Estados, abarca-se um maior número de instituições: por exemplo em Espanha, as disposições legislativas abrangem museus, fonotecas, filmotecas, hemerotecas e arquivos; na Itália, as bibliotecas, estabelecimentos docentes, museus e arquivos e, finalmente, em Luxemburgo, as bibliotecas, instituições educativas, museus e arquivos.

Os quinze Estados membros mais antigos da União Europeia, aqui referenciados, apresentam algumas diferenças quanto ao direito de reprodução e ao direito de comunicação, mais concretamente, quanto ao tipo de obras que são consideradas, mas só alguns permitem a cópia digital.

No que diz respeito ao direito de reprodução, a Alemanha, a Bélgica, a Dinamarca, a Finlândia, a França, a Grécia, a Holanda, a Irlanda, a 
Itália, Portugal, Reino Unido e, por último, a Suécia permitem cópias das obras das colecções. A Alemanha, a Irlanda, o Reino Unido e a Suécia aludem, também, às cópias de artigos publicados. A Áustria, a Bélgica e a Dinamarca possibilitam as cópias de obras publicadas e alguns Estados, como a Dinamarca e o Reino Unido englobam, ao mesmo tempo, as cópias de obras não publicadas. A Finlândia abrange a realização de cópias consideradas vulneráveis. A cópia digital não é permitida na Itália.

Quanto ao direito de comunicação pública das obras, constata-se que a Alemanha, a Bélgica, a Dinamarca, a Espanha, a Finlândia, a Holanda, a Itália, o Luxemburgo e Portugal incluem nos seus diplomas legislativos o direito de comunicação pública das obras das colecções das bibliotecas, sempre que a licença o permitir. A Áustria, a França, a Grécia, a Irlanda, o Reino Unido e a Suécia não prevêem estas disposições nas suas legislações.

A nível do empréstimo, a Alemanha, a Áustria, a Bélgica, a Dinamarca, a Finlândia, a França, o Luxemburgo, Portugal e, por fim, a Suécia não o contemplam nas suas legislações. Apenas a Espanha, a Grécia, a Holanda, a Irlanda, a Itália, o Reino Unido incluem as disposições sobre o empréstimo nas suas medidas legislativas.

\section{Análise comparativa dos países da América Latina}

$\mathrm{Na}$ análise dos países da América Latina, introduziu-se mais uma variável. Ao contrário dos países europeus, nem todos os países da América Latina incluem nas suas legislações uma excepção em favor das bibliotecas, razão pela qual se introduziu como primeira variável. Na situação desta excepção ser incluída nas legislações dos países, as restantes variáveis utilizadas para proceder à análise são as mesmas, que foram utilizadas na anterior tabela, tais como a finalidade, o tipo de instituições, as classes de obras e o empréstimo público. O resumo desta análise, aparece representado na TAB. 2 .

TABELA 2 As excepções para as Bibliotecas na legislação de América Latina

\begin{tabular}{l|l|l|l|l|l|l}
\hline Países & $\begin{array}{c}\text { Excepções } \\
\text { para as } \\
\text { Bibliotecas }\end{array}$ & Finalidade & $\underline{\text { Instituiç̃ós }}$ & Reprodução & $\begin{array}{l}\text { Comunicação } \\
\text { Pública }\end{array}$ & Empréstimo \\
\hline Argentina & Não & ----- & ----- & ----- & ----- & ---- \\
\hline Bolívia & Sim & $\begin{array}{l}\text { Preservação } \\
\text { Substituição }\end{array}$ & $\begin{array}{l}\text { Bibliotecas e } \\
\text { Arquivos }\end{array}$ & $\begin{array}{l}\text { Obras da } \\
\text { colecção }\end{array}$ & Não & Não \\
\hline Brasil & Não & ----- & ------ & ----- & ----- \\
\hline Colômbia & Sim & $\begin{array}{l}\text { Preservação } \\
\text { Copias para } \\
\text { outras } \\
\text { bibliotecas }\end{array}$ & $\begin{array}{l}\text { Bibliotecas e } \\
\text { Arquivos }\end{array}$ & $\begin{array}{l}\text { Obras da } \\
\text { colecção }\end{array}$ & Não & Não \\
\hline Chile & Não & ----- & ----- & ----- & ----- & ---- \\
\hline
\end{tabular}




\begin{tabular}{|c|c|c|c|c|c|c|}
\hline Equador & Sim & \begin{tabular}{|l} 
Preservação \\
Substituição
\end{tabular} & $\begin{array}{l}\text { Bibliotecas e } \\
\text { Arquivos }\end{array}$ & $\begin{array}{l}\text { Obras da } \\
\text { colecção }\end{array}$ & Não & Não \\
\hline México & Sim & \begin{tabular}{|l|} 
Segurança \\
Preservação
\end{tabular} & $\begin{array}{l}\text { Bibliotecas e } \\
\text { Arquivos }\end{array}$ & $\begin{array}{l}\text { Obras } \\
\text { divulgadas }\end{array}$ & Não & Não \\
\hline Paraguai & Sim & \begin{tabular}{|l|} 
Preservação \\
Substituição
\end{tabular} & $\begin{array}{l}\text { Bibliotecas e } \\
\text { Arquivos }\end{array}$ & $\begin{array}{l}\text { Obras da } \\
\text { colecção }\end{array}$ & Não & Sim \\
\hline Peru & Sim & $\begin{array}{l}\text { Preservação } \\
\text { Substituição }\end{array}$ & $\begin{array}{l}\text { Bibliotecas e } \\
\text { Arquivos }\end{array}$ & $\begin{array}{l}\text { Obras da } \\
\text { colecção }\end{array}$ & Não & Sim \\
\hline Uruguai & Não & ----- & ----- & ----- & ----- & ----- \\
\hline Venezuela & Sim & $\begin{array}{l}\text { Preservação } \\
\text { Substituição }\end{array}$ & $\begin{array}{l}\text { Bibliotecas e } \\
\text { Arquivos }\end{array}$ & $\begin{array}{l}\text { Obras da } \\
\text { colecção }\end{array}$ & Não & Não \\
\hline
\end{tabular}

Fonte: Dados da pesquisa.

Primeiramente, o que chama a atenção reside no facto de 4 dos países mais desenvolvidos da região e, mais precisamente, membros do Mercosul, como é o caso da Argentina, do Brasil, do Chile e do Uruguai, carecerem nas suas leis de direito de autor, das excepções a favor das bibliotecas ou instituições similares. Este aspecto resulta mais surpreendente e merece uma valorização ainda mais negativa, se tivermos em conta que só 21 , dos 149 países analisados no estudo da OMPI (CREWS, 2008), não apresentam nenhuma excepção em benefício das bibliotecas.

Outra conclusão que se pode extrair consiste na semelhança da legislação dos 4 países, que formam a Comunidade Andina: Bolívia, Colômbia, Equador e Peru. A este respeito, importa ter presente a Decisión 351 (COMUNIDAD ANDINA, 1993), que estabelece um "Régimen Común sobre Derechos de Autor y Derechos Conexos", cujo artigo 22.c introduz, de forma explícita, uma excepção a favor das bibliotecas e arquivos, sem fins lucrativos. Concretamente, permite reproduzir uma obra quando o exemplar respectivo pertença à sua colecção permanente e se realize com a finalidade de preservação ou de substituição, nos casos do exemplar se ter extraviado, destruído ou inutilizado.

Ainda que não pertençam a este Pacto Andino, seguem a mesma orientação as legislações do México, do Paraguai e da Venezuela. Assim, em 7 países que apresentam incluídas nas suas legislações, as excepções em benefício das bibliotecas, os fins pelos quais se pode efectuar cópias das obras consistem na preservação e na substituição de exemplares perdidos ou deteriorados, exigindo-se que as bibliotecas ou os arquivos não possuam qualquer finalidade económica, quer directa ou indirectamente e, ainda, requer-se que a obra a copiar pertença, de forma lícita, à colecção permanente das ditas instituições. As legislações destes países estabelecem que só se pode realizar uma cópia de uma obra, que se quer preservar ou substituir, resultando claramente insuficiente, especialmente no caso das obras digitais. Podemos referir, como exemplo, que a lei dos Estados Unidos permite a realização de três cópias por razões de preservação. 
Também coincidem todas estas leis, na ausência de uma excepção ao direito de comunicação pública. Trata-se, sem dúvida, de um dos elementos que mostram que a lei se encontra ou não adaptada ao ambiente digital. Pois bem, nenhum destes países limita este direito, ao contrário de uma boa parte dos países europeus.

Não obstante estas semelhanças, também, se podem observar algumas diferenças significativas. Por exemplo, a lei do México é a única que não refere, explicitamente, que devem ser obras da colecção. Apenas referencia 'obras divulgadas' (artigo 148), o que implica uma maior abrangência. Também, é notável que a legislação colombiana, no seu artigo 38, estipula os fins para conservação, admitindo, ainda, a cópia necessária para os empréstimos a outras bibliotecas, no caso de serem obras esgotadas no mercado. Permite, também, a realização da cópia pela biblioteca que a recebe, no caso de que seja preciso para a sua conservação e com o fim de ser usada pelos utilizadores.

Um aspecto muito importante reside numa excepção que permite que o empréstimo público se encontre dissociado do direito de distribuição, algo habitual na maioria dos países desenvolvidos. Pois bem, somente as leis do Paraguai e do Peru incluem esta excepção. Resulta curioso que o texto seja idêntico em ambos os casos (artigo 39.5, no caso do Paraguai e artigo 43.f, no Peru): sem autorização do autor, é permitido "el préstamo al público del ejemplar lícito de una obra expresada por escrito, por una biblioteca o archivo cujas actividades no tengan directa o indirectamente fines de lucro" A valorização não pode ser mais negativa: como é possível que só estes dois países considerem que o empréstimo, que é realizado pelas bibliotecas, deva estar isento da autorização dos titulares dos direitos?

Definitivamente, a análise pormenorizada da legislação dos países da América Latina permite-nos concluir que o seu conteúdo é pobre e escasso, em virtude de, normalmente, só permitir efectuar cópias por razões de preservação e de conservação, sem chegar mais longe, nem amparar outro tipo de actividades bibliotecárias. Outro aspecto a destacar, reside no facto de nenhuma das legislações ter sido modificada para fazer frente aos problemas do ambiente digital, razão pela qual, o seu conteúdo encontra-se, claramente, obsoleto. Neste sentido, é muito significativo que nenhuma das legislações tenha considerado o direito de comunicação pública, apenas incidiram sobre a reprodução, o que equivale a uma visão, absolutamente, pré-digital. Este aspecto é importante, na medida em que as leis foram reformadas recentemente, em alguns casos e se introduziram novidades, como é o caso da protecção tecnológica (ainda sem excepções) e, convém relembrar que todos os países, menos o Brasil, assinaram o Tratado da OMPI de 1996.

\section{Considerações finais}

Os bibliotecários respeitam os direitos de autor e, como regra geral, comportam-se como utilizadores responsáveis dos recursos informativos 
que compõem as suas colecções, facilitando o seu uso para a educação, a investigação e o trabalho dos cidadãos. Infelizmente, não parece ter entendido assim, o legislador da maioria dos países: na actualidade, as excepções a favor das bibliotecas são insuficientes e encontram-se pouco adaptadas à nova realidade tecnológica. Esta inadequação da legislação pressupõe uma enorme dificuldade, para que continuem cumprindo as suas funções, sem infringir a lei.

Não obstante, verificam-se importantes diferenças entre uns países e outros. Da nossa análise comparativa, se extrai que as leis dos países da União Europeia se encontram mais actualizadas e protegem melhor os interesses das bibliotecas e dos cidadãos, do que as leis dos países latinoamericanos. Especialmente grave é o caso da Argentina, do Brasil, do Chile e do Uruguai, em cujas leis nem sequer surgem as excepções que beneficiam as bibliotecas, querendo isto significar, que pertencem, aproximadamente, aos $10 \%$ dos países do mundo que não as contemplam.

Se uma legislação de direitos de autor desequilibrada e sem as adequadas excepções aos direitos, resulta de forma negativa, num país desenvolvido, muito mais o será, num país em vias de desenvolvimento, por ser mais importador que exportador de produtos com direitos de autor. Deste modo, os países deviam ter uns sistemas de direitos de autor menos proteccionistas e mais adaptados a circunstâncias concretas.

Tanto os países europeus como os da América Latina deveriam aproveitar as possibilidades legais oferecidas pelo Tratado de Direito de Autor da OMPI, de 1996, para ampliar e adaptar as excepções ao novo ambiente tecnológico. Neste trabalho, os países latino-americanos deveriam ter em conta que o seu nível de desenvolvimento é distinto, pelo que as suas leis não deveriam ser simples cópias das daqueles países mais ricos.

\section{Reconhecimentos}

Este trabalho tem o apoio do Ministerio de Ciencia e Innovación de España, Projeto CSO-2008-03817/SOCI.

\section{Referências}

COMUNIDAD ANDINA. Régimen común sobre derecho de autor y derechos conexos. Decisión $351 . \quad 1993 . \quad$ Disponível em: $<$ http://www.comunidadandina.org/normativa/dec/d351.htm $>$. Acesso em: 18 jan. 2010.

CREWS, K. Estudio sobre las limitaciones y excepciones al derecho de autor en beneficio de bibliotecas y archivos (Comité Permanente de Derecho de Autor y Derechos Conexos, OMPI). 2008. Disponível em: $<$ http://www.wipo.int/edocs/mdocs/copyright/es/sccr $17 / \mathrm{sccr} 17$ 2.pdf $>$ . Acesso em: 18 jan. 2010. 
DREIER, T. Towards consensus on the electronic use of publications in libraries. Göttingen: SUB, 2001.

EIFL. Draft law on copyright. Including model exceptions and limitations for libraries and consumers. Based on WIPO draft law on copyright and related rights (version 2005). 2009. Disponível em: <http://plip.eifl.net/docs/ip docs/draft-law>. Acesso em: 18 jan. 2010.

FERNÁNDEZ-MOLINA, J. C. Derecho de autor y bibliotecas digitales: a la búsqueda del equilibrio entre intereses contrapuestos. Transinformação, v. 20, n. 2, p.123-131, 2008.

FERNÁNDEZ-MOLINA J. C. Protección tecnológica y privilegios de las bibliotecas: regulación en la legislación de derecho de autor de los países de la Unión Europea. Nuovi Annali della Scuola Speciale per Archivisti e Bibliotecari, v. 23, p. 225-240, 2009.

FERNÁNDEZ-MOLINA, J. C.; DIAS, M. C.; BORGES, M. M. Bibliotecas y derechos de autor: análisis comparativo de la nueva legislación de España y Portugal. In: FRÍAS, J. A.; TRAVIESO, C. (Eds). Información, investigación y mercado laboral en información y documentación en España y Portugal. Salamanca: Universidad de Salamanca, 2008. p. 801811.

GARROTE, I. El derecho de autor en Internet. La directiva sobre derechos de autor y derechos afines en la sociedad de la información. Granada: Comares, 2001.

GARRETT, J. B. S. L. A. Relatório do Projecto de Lei apresentado por Garrett na Câmara dos Deputados em 18 de Maio de 1839. Lisboa: [s.n.], 1839 apud PEREIRA, A. D. Informática, direito de autor e propriedade tecnodigital. Coimbra: Coimbra Editora, 2001.

GUIBAULT, L. Copyright limitations and contracts: an analysis of the contractual overridability of limitations on copyright. The Hague: Kluwer Law International, 2002.

GUIBAULT, L. The nature and scope of limitations and exceptions to copyright and neighbouring rights with regard to general interest missions for the transmission of knowledge: prospects for their adaptation to the digital environment. e-Copyright Bulletin, 2003. Disponível em: $<$ http://unesdoc.unesco.org/images/0013/001396/139671e.pdf $>$. Acesso em: 18 jan. 2010.

IFLA. Statement of principles on copyright exceptions and limitations for libraries and 2009. Disponível em: $<$ http://www.ifla.org/files/clm/statements/statement-of-principlessccr20.pdf>. Acesso em: 18 jan. 2010.

LIBRARY COPYRIGHT ALLIANCE. Library-related principles for the International Development Agenda of the World Intellectual Property Organization. 2004. Disponível em: 
<http://www.librarycopyrightalliance.org/wipo.htm $>$. Acesso em: 18 jan. 2010.

LIBRARY OF CONGRESS. The Section 108 Study Group Report. 2008. Disponível em:

<http://www.section108.gov/docs/Sec108StudyGroupReport.pdf>.

Acesso em: 18 jan. 2010.

OMPI. Convenio de Berna para la protección de las obras literarias y artísticas. $<$ http://www.wipo.int/treaties/es/ip/berne/trtdocs wo001.html $>$. Acesso em: 18 jan. 2010.

OMPI. Tratado de la OMPI sobre Derecho de Autor. 1996. Disponível em: http://www.wipo.int/treaties/es/ip/wct/trtdocs wo033.html. Acesso em: 18 Jan. 2010.

PEREIRA, A. D. Informática, direito de autor e propriedade tecnodigital. Coimbra: Coimbra Editora, 2001.

RICKETSON, S. WIPO study on limitations and exceptions of copyright and related rights in the digital environment. Standing Committee on Copyright and Related Rights. Ninth Session. Geneva, June 23 to 27. 2003. Disponível em: <http://www.wipo.int/edocs/mdocs/copyright/en/sccr 9/sccr 9 7.pdf>. Acesso em: 18 jan. 2010.

STEWART, S. M. International copyright and neighbouring rights. $2^{\text {nd }}$ ed. London: Butterworths, 1989.

UNESCO. Manifesto da UNESCO sobre Bibliotecas Publicas. 1994. Disponível em: <http://www.ifla.org/VII/s8/unesco/port.htm>. Acesso em: 18 jan. 2010.

UNIÃO EUROPEIA. Directiva 2001/29/CE, do Parlamento Europeu e do Conselho, de 22 de Maio de 2001, relativa à harmonização de certos aspectos do direito de autor e dos direitos conexos na sociedade da informação. Jornal Oficial das Comunidades Europeias. Série L, n. 167. 2001. Disponível em: <http://eurlex.europa.eu/LexUriServ/LexUriServ.do?uri=OJ:L:2001:167:0010:0019:P T:PDF>. Acesso em: 18 jan. 2010. 